\title{
Point-of-care ultrasound and Doppler ultrasound evaluation of vascular injuries in penetrating and blunt trauma
}

\author{
Miguel Angel Montorfano ${ }^{1 *}$, Fernando Pla', Leonardo Vera' , Omar Cardillo', Stefano Geniere Nigra² \\ and Lisandro Miguel Montorfano'
}

\begin{abstract}
Background: The aim of this study is to describe point-of-care ultrasound and Color flow Duplex Doppler characteristics of penetrating and blunt trauma-related vascular injuries of the limbs and neck.

Methods: Penetrating and blunt trauma-related vascular injuries such as vein disruption, intimal flap, deep vein thrombosis, arterial dissection, pseudoaneurysm, and arteriovenous fistulae are discussed in this manuscript. Images of the most significant lesions of our personal clinical experience are presented to illustrate point-of-care ultrasound and Color flow Duplex Doppler ultrasound findings.

Results: Penetrating and blunt trauma-related vascular injuries represent a big challenge. While patients with hard signs of arterial damage must be sent immediately to surgical exploration, when there are soft signs or no clear signs of vascular injury at the physical examination, and the patient is stable, imaging investigation and observation can be useful in the diagnosis and management of these patients. Although angiography is the gold standard of the imaging methods, point-of-care ultrasound and Color flow Duplex Doppler ultrasound are widely available, cheaper, noninvasive, and faster to obtain. They can provide bedside valuable information for the identification of some vascular injuries allowing to an integrated management of the trauma patient, enriched by the use of ultrasound.
\end{abstract}

Conclusions: Point-of-care ultrasound and Color flow Duplex Doppler examination are increasingly used in the decision making process of trauma-related vascular injuries.

Keywords: Doppler sonography, Color flow Duplex Doppler, Critical ultrasound, Point-of-care ultrasound, Vascular injury, Trauma

\section{Background}

Injuries are an important public health problem worldwide. More than 5 million people die each year as a result of injuries. This accounts for $9 \%$ of the world deaths, nearly 1.7 times the number of fatalities that result from HIV/AIDS, tuberculosis, and malaria combined. Among the causes of injury are traffic accidents, interpersonal violence, burns, drowning, falls, and poisonings.

\footnotetext{
*Correspondence: miguel.montorfano@winfocus.org

1 Present Address: Department of Ultrasound, Clemente Álvarez

Emergency Hospital, Av. Pellegrini 3205, 2000 Rosario, Santa Fe, Argentina

Full list of author information is available at the end of the article
}

A quarter of the deaths are the result of traffic injuries, while suicide and homicide account for nearly another quarter.

For every person who died as a result of violence, many more are injured, causing a rise in costs in health care systems and in a massive burden in national economies [1]. Moreover, violence exacts a high cost on global development [2].

More than $90 \%$ of injury-related deaths occur in lowand middle-income countries and in remote locations.

Increase in urban crime and violence are affecting the lives of millions of people in Latin America. 
The Pan American Health Organization called violence in Latin America "the social pandemic of the 20th century" [3].

Social inequality and substantial increase in the size of drug markets are considered major contributing factors to the levels of violence in Latin America. Of the world's 50 most dangerous cities, 43 are located in Latin America and the Caribbean.

Although the main goal must be to prevent injuries and violence from happening, a quick and rapid diagnosis and treatment are essential to prevent fatalities and reduce disabilities [1].

Vascular injuries represent less than $3 \%$ of all traumatic findings, yet they are associated with potentially severe complications [4-9]. If not recognized and treated fast, injuries to major arteries and veins may have devastating consequences resulting in amputations or even death. Knowing the mechanism of the trauma is of extreme importance for making the correct diagnosis. Although blunt trauma is a common cause of acute trauma presentation in the civil population worldwide, the increasing urban violence in our region has produced a rise of penetrating trauma produced by gun shot and stab wounds that deserve especial considerations (Fig. 1). Most vascular injuries are caused by penetrating trauma, such as gunshot wounds, stabbing, and blast injuries [6]. Blunt trauma causes significant soft tissue injury, while vascular disorders are less frequent [4]. Nonetheless, also in blunt trauma, vascular injuries need to be ruled out, especially in patients with displaced long bone fractures, crush injuries, and patients with prolonged immobilization [4-7]. Blunt trauma is more often associated with partial or complete vascular occlusion, arterial dissections, and intimal flaps, while penetrating trauma can also cause pseudoaneurysms, arteriovenous fistulas, and vein thrombosis [10-13].

The majority of vascular injuries are located in the extremities. Vascular injuries present a great challenge to emergency physicians because some vascular lesions may not be immediately identified with clinical evaluation and monitoring of vital signs.

The presence of "hard signs" in the physical examination" (such as pulsatile external bleeding, expanding haematoma, absent distal pulses, cold/pale limb, palpable thrill, or audible bruit) is an indication of immediate surgical intervention.

When the site or presence of a vascular injury is less obvious, the patient is stable and there are no signs or just soft signs of vascular injuries (such as peripheral nerve deficit, history of moderate hemorrhage at scene, a reduced but palpable pulse, or an injury in proximity to a major artery) imaging investigation and observation can be useful in the diagnosis and management of these patients. [4, 14].

Angiography is the gold standard for the evaluation of trauma-related vascular injuries; however, other noninvasive imaging methods such as computer tomography angiogram, magnetic resonance angiography, and Doppler ultrasound have emerged in recent years as valid alternatives [15].

Color flow Duplex Doppler is a widely available and reliable method with high sensitivity (95-97\%), specificity (95-98\%), and accuracy (98\%) in assessment of peripheral vascular injuries $[15,16]$.

Bergstein et al. compared Color flow Doppler with arteriography in 67 patients without obvious vascular injuries. Using arteriography as the gold standard, Color flow Doppler had a specificity of $99 \%$, sensitivity of $50 \%$,
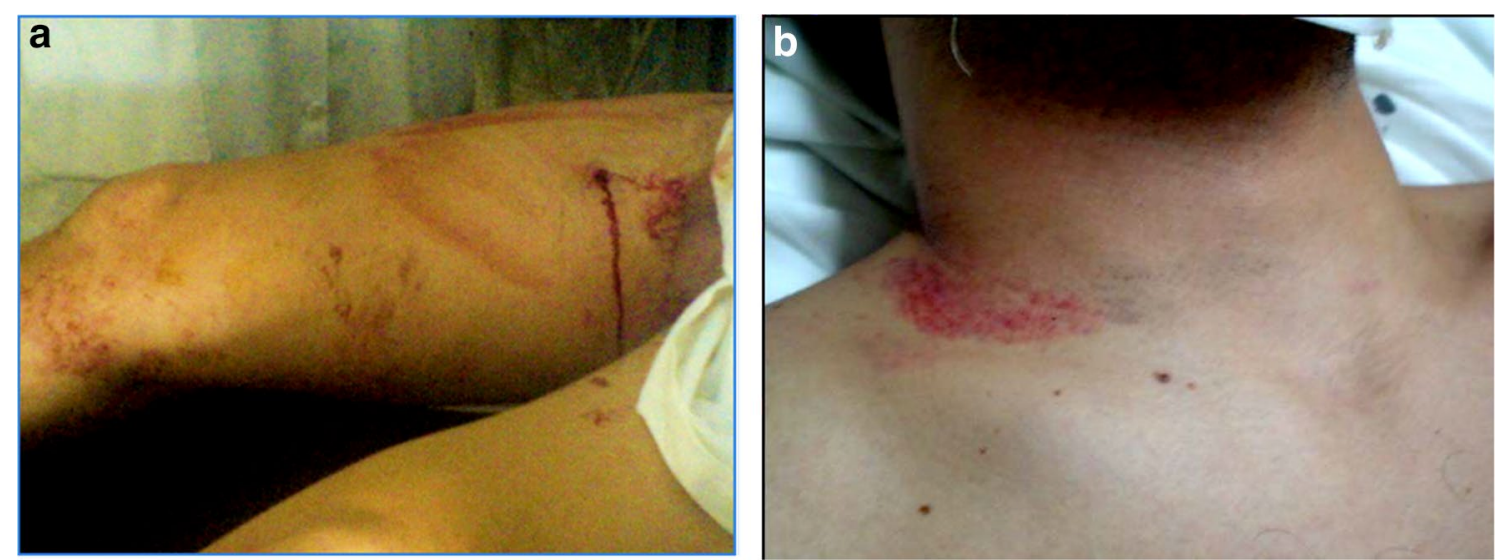

Fig. 1 a Penetrating wound in the leg: gun shot wound. b Blunt trauma of the neck 
and negative and positive predictive values of 66 and 7\%, respectively [16].

Fry et al. described $100 \%$ sensitivity and specificity of Duplex Doppler compared with the conventional arteriography and operative exploration [17].

In a recent study, Mohd Wani et al. evaluate with Color flow Duplex Doppler 150 patients with soft signs of vascular injury of the limbs. The patients with features of vascular injury on Color Doppler (110 patients) were subjected to exploration, while patients who had normal Doppler (40 patients) were subjected to CT- angiography. Color flow Doppler had a sensitivity of $94 \%$ and specificity of $82.5 \%$ in diagnosis of vascular injury compared with CT angiography and surgical exploration [18].

Point-of-care ultrasound is widely available in trauma centers, emergency departments and is increasingly being used in the prehospital setting and in remote locations. In many cases, it is the first diagnostic method available. In these scenarios, it is used for a whole body examination, from head to toe, allowing to an integrated management of the trauma patient [19].

In the extremities and neck Point of care ultrasound is used for the diagnosis of fractures, hematomas, and the identification of foreign bodies [20]. At the same time we propose that, in stable patients without hard signs of vascular damage, it could be of great help for a prompt bedside diagnosis, characterization, and monitoring of trauma-related vascular injuries.

\section{The technique}

Vascular injuries of the extremities and neck must be investigated with high-frequency linear transducers because a higher resolution and a lower penetration are commonly needed. There are some exceptions, such as patients with large hematomas and super obese patients, in which a convex probe with higher penetration is recommended. When evaluating vascular injuries, we have to explore the region of the trauma, and transversal and longitudinal scans of the vessels should be performed with B-mode. Proximal and distal flows should be investigated with Color flow Duplex Doppler ultrasound. For comparative purposes, both limbs and both sides of the neck should be evaluated.

Normal veins usually are oval in shape and completely compressible with a controlled pressure of the probe. The pulsed wave Doppler analysis shows a continuous flow pattern with respiratory variations.

Normal arteries are round in shape, with an echogenic wall, and noncompressible with the probe. Arteries of the extremities show a triphasic pattern in the pulsed Doppler spectrum. The triphasic pattern has a first positive phase related with the systole of the left ventricle, a second negative phase related with the closure of the aortic valve, and a third positive phase produced by the elasticity of the arterial walls. The loss of this triphasic pattern is always pathologic [21, 22]. The absence of triphasic pattern can be acute (traumatic injury or obstruction) or chronic (atherosclerosis, diabetes, aging).

Although in trauma patients, the presence of obesity, large hematomas, subcutaneous air, or large open wounds of the skin can represent a technical limitation to the penetration of the sound waves, with point-of-care ultrasound and Color flow Duplex Doppler is possible to accurately rule in or rule out trauma-related vascular injuries, $[15,16,23,24]$.

The aim of this study is to review and describe point-ofcare ultrasound and Doppler ultrasound characteristics of penetrating and blunt trauma-related vascular injuries of the limbs and neck, such as vein rupture, intimal flap, deep vein thrombosis, arterial dissection, pseudoaneurysm, and arteriovenous fistulae. A bedside identification of these lesions can help to a better care of these patients. Images of most significant lesions are presented to illustrate point-of-care ultrasound and Doppler ultrasound findings.

\section{Pathologic sonographic patterns}

In patients with clinical suspicion of a vascular injury, point-of-care ultrasound and Doppler ultrasound are used to answer 2 basic questions:

1. Does the patient have a vascular lesion? Yes or no?

2. If the answer is yes: what kind of lesion?

Ultrasound can rapidly rule out vascular injuries after trauma at the bedside (Figs. 2, 3, 4).

When there is a trauma-related vascular lesion three basic patterns can be identified:

- Venous injuries

- Arterial injuries

- Mixed arterial and venous injuries

\section{Venous injuries}

Normal veins are anechoic and easily totally compressible by ultrasound transducers [21, 22, 25]. Traumatized veins may suffer partial or complete disruption, intimal injury, or post-traumatic thrombosis and this may alter the normal characteristics of these vessels. In complete disruption, it might be difficult to identify the site of injury due to shrinkage of injured veins or vein compression by the resultant hematoma. The presence of hematoma in the anatomical site where a major large caliber vein is supposed to be seen without a clear visualization of the vein is a strong indicator of complete vein rupture. In some blunt trauma patients, the ultrasonographic 


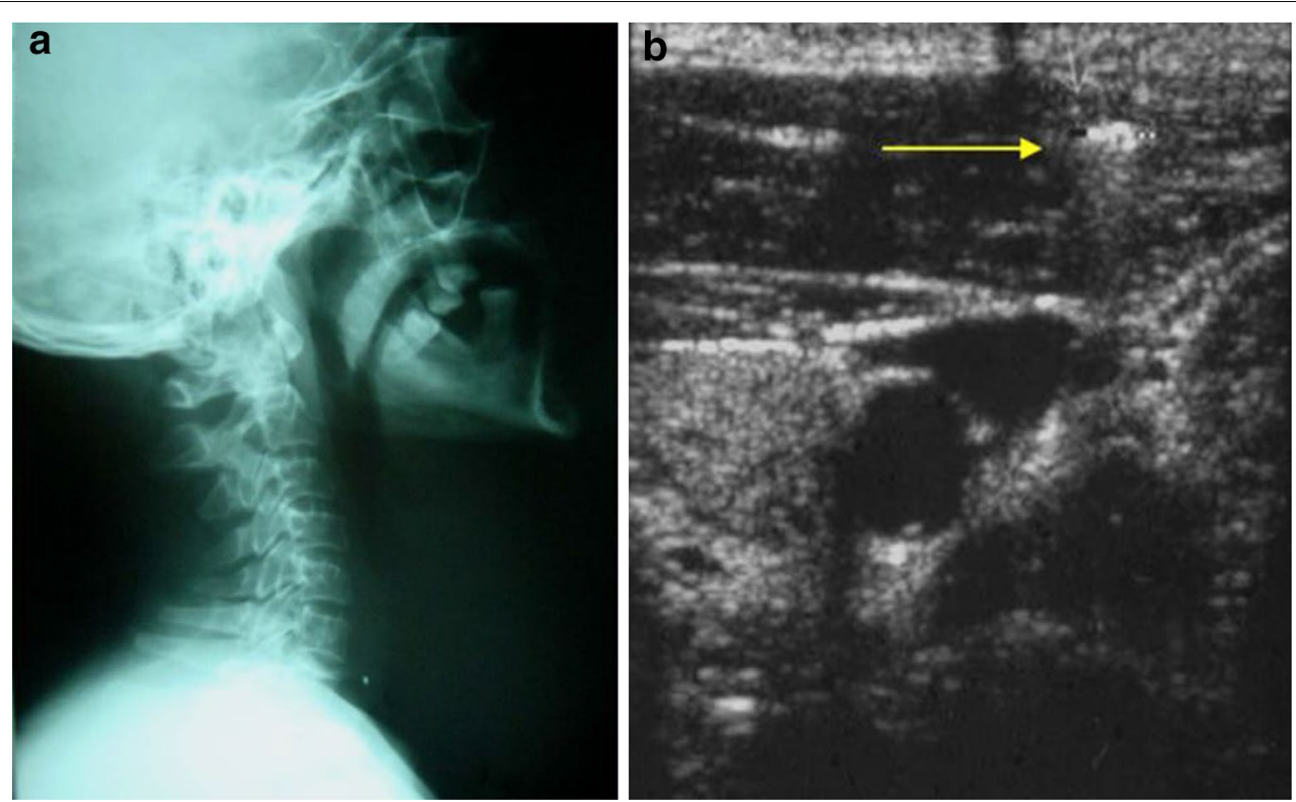

Fig. 2 No vascular compromise: B mode. a X ray showing a bullit in the base of the neck. b Mode showing the bullit in the esternocleidomastoid muscle. No vascular compromise of the jugular vein nor the carotid artery

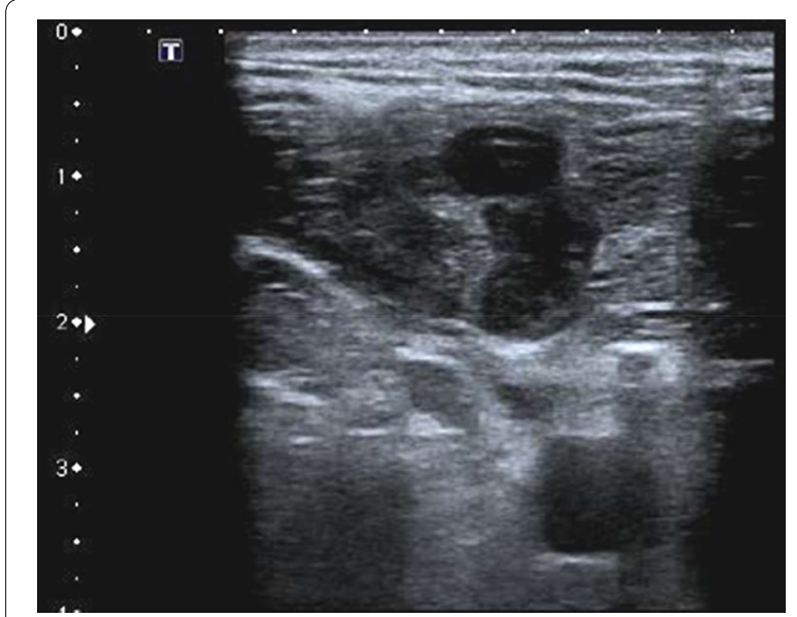

Fig. 3 Soft tissue hematoma of the left side of the neck. No vascular injury

identification of a venous intimal flap injury may occur (Fig. 5).

Other common injury in trauma patients is vein thrombosis. When present, it usually appears after minutes or hours after the trauma. For the identification and diagnosis of venous thrombosis, we can use the compression technique and the Color Duplex Doppler evaluation [25-30].
In cases of acute thrombosis, the vein appears dilated, anechoic, and is not compressible (Fig. 6). In chronic thrombosis, the thrombus appears more echogenic and the vein is not dilated. Occasionally, in chronic thrombosis, the vein is partially collapsible, due to partial thrombosis or, in chronic thrombosis, because of the presence of channels within the thrombus, that leave the blood pass through (thrombus channeling or tunneling) (Fig. 7).

Color Duplex Doppler evaluation will show the presence or absence of blood flow and the direction and velocity of the flow. In normal veins, the flow is continuous and spontaneous at rest and the velocity varies with respiration, increasing during inspiration, and decreasing during expiration or when a Valsalva maneuver is performed. The active compression of distal segments of the legs will cause an increase or "augmentation" of the velocity of the venous flow (Fig. 8). In case of partial thrombosis, the flow may be normal or pathologic, losing the variability during respiration. In total occlusive thrombosis, there will be complete absence of flow in color Doppler and in the spectral analysis.

\section{Arterial injuries}

In most cases, blunt and penetrating traumas cause only a slight wall irregularity (Fig. 9). When a serious injury occurs, intimal detachments, pseudoaneurysms, or arteriovenous fistula may occur. 

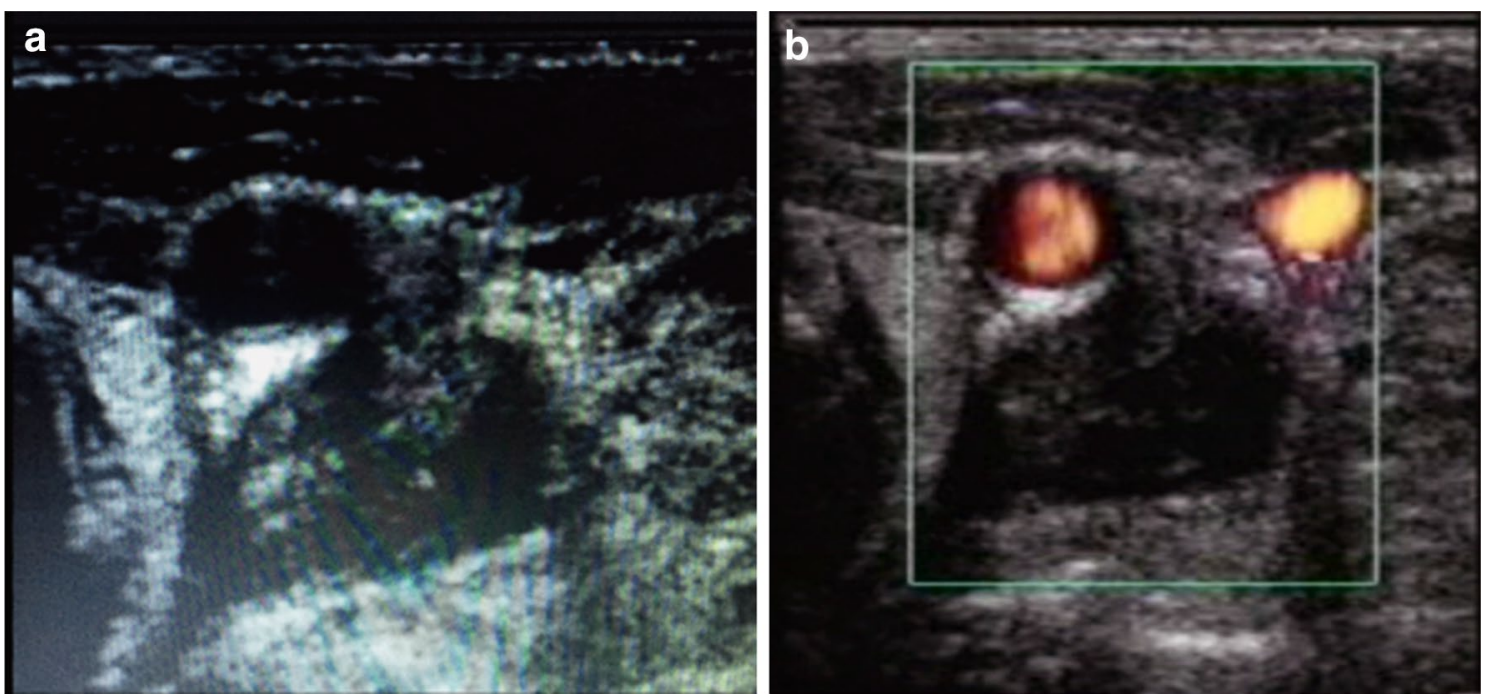

Fig. 4 Perivascular hematoma. Knife penetrating wound in the left side of the neck. a Transverse view of the neck showing an hypoecoic hematoma between carotid and yugular vein. b Power Doppler showing indemnity of carotid and yugular with the hemathoma between the two vessels

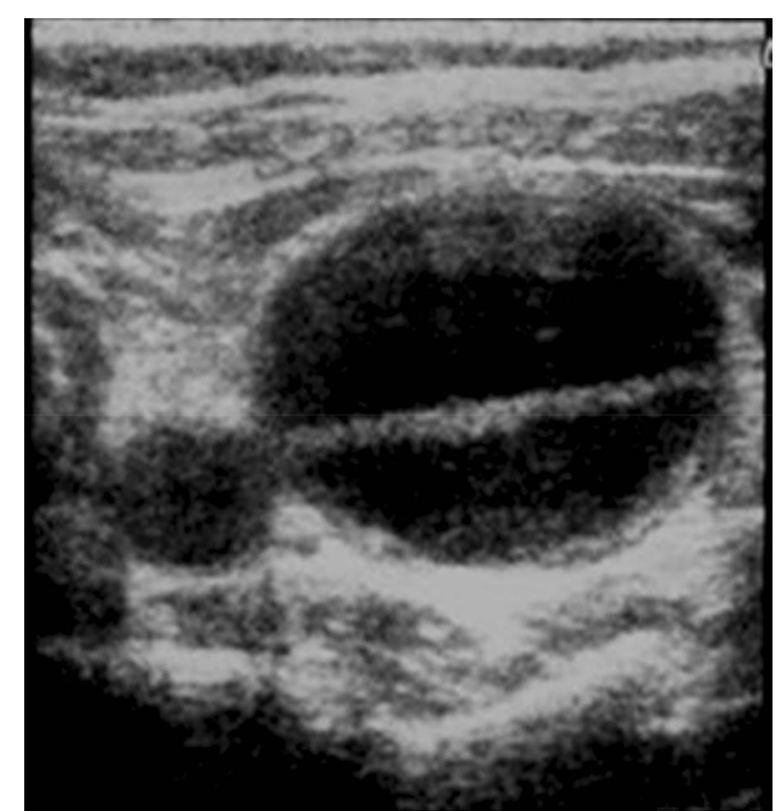

Fig. 5 Blunt trauma to the neck. Transverse view of the left side of the neck showing the carotid artery and a dilated jugular vein with with detachment of the wall
Regarding intimal flaps, they appear as thin, echogenic structures swimming within the vessel lumen (Fig. 10). In some cases, depending on the size of the intimal flap, PWD and CFD may show turbulence and irregular flow (Fig. 11). The usual approach for most cases is to wait and see, supplemented or not with antiplatelet medication, and a strict follow-up [31, 32]. Endovascular management of intimal defects has also been proposed [32] Occasionally, these injuries can progress to arterial thrombosis. The presence of arterial thrombosis is observed in B-mode as echogenic material occupying arterial lumen. Doppler examination may show no flow both in PWD and CFD mode (Fig. 12).

A pseudoaneurysm is produced by the partial rupture of an artery wall, which causes accumulation of periarterial blood, surrounded and contained by the adventitia, hematomas, or soft tissue. It is always in communication with the arterial lumen by a small portion called pseudoaneurysm neck. The most common cause is an interventional medical procedure [15, 33]. Penetrating trauma, by gunshot or stab wound, is other very common cause [34, 35]. Using the B-mode, the presence of 


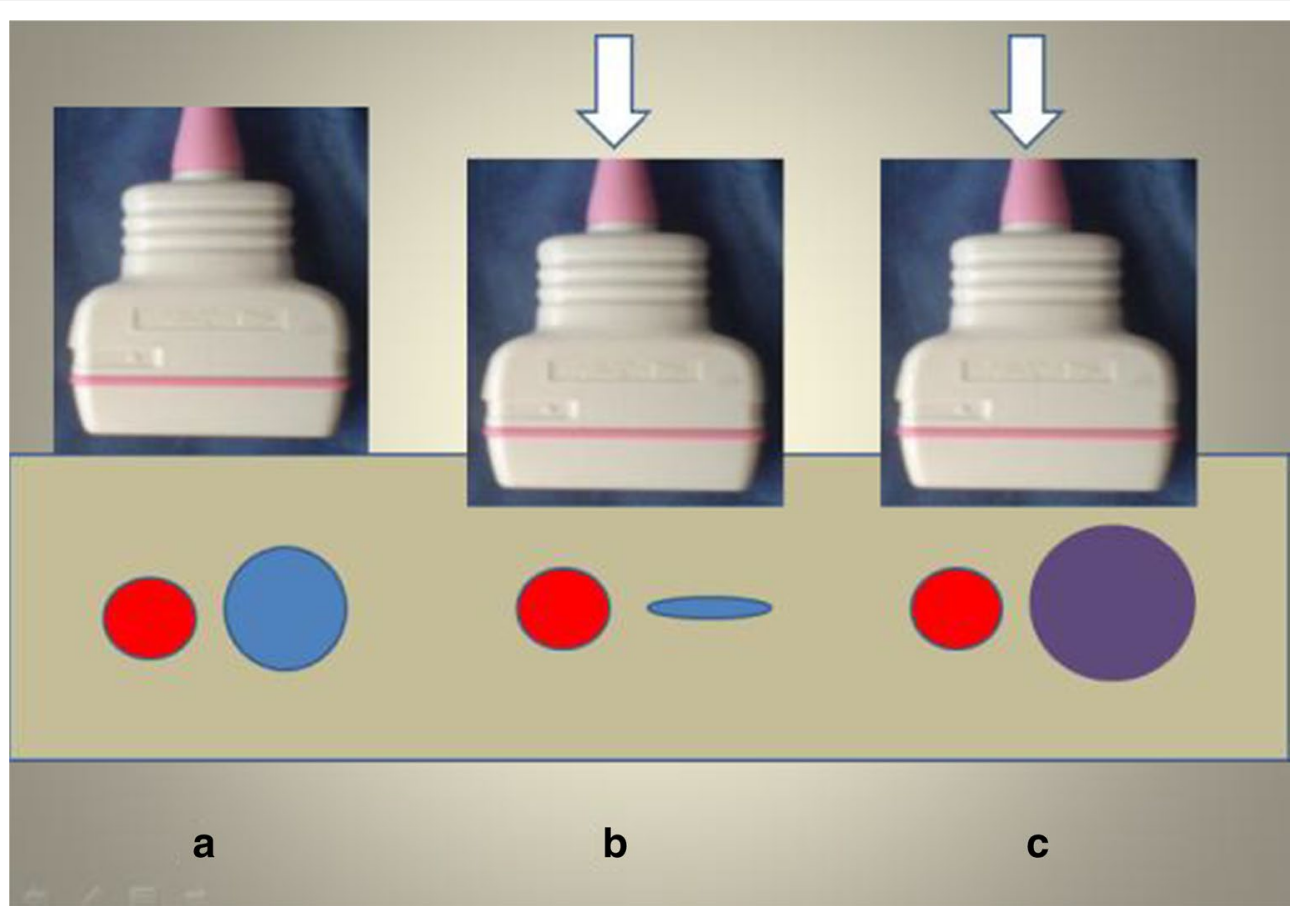

Fig. 6 Schematic representation of the compression vein technique. a Without compression, b compressive normal vein, c non compressive venous thrombosis
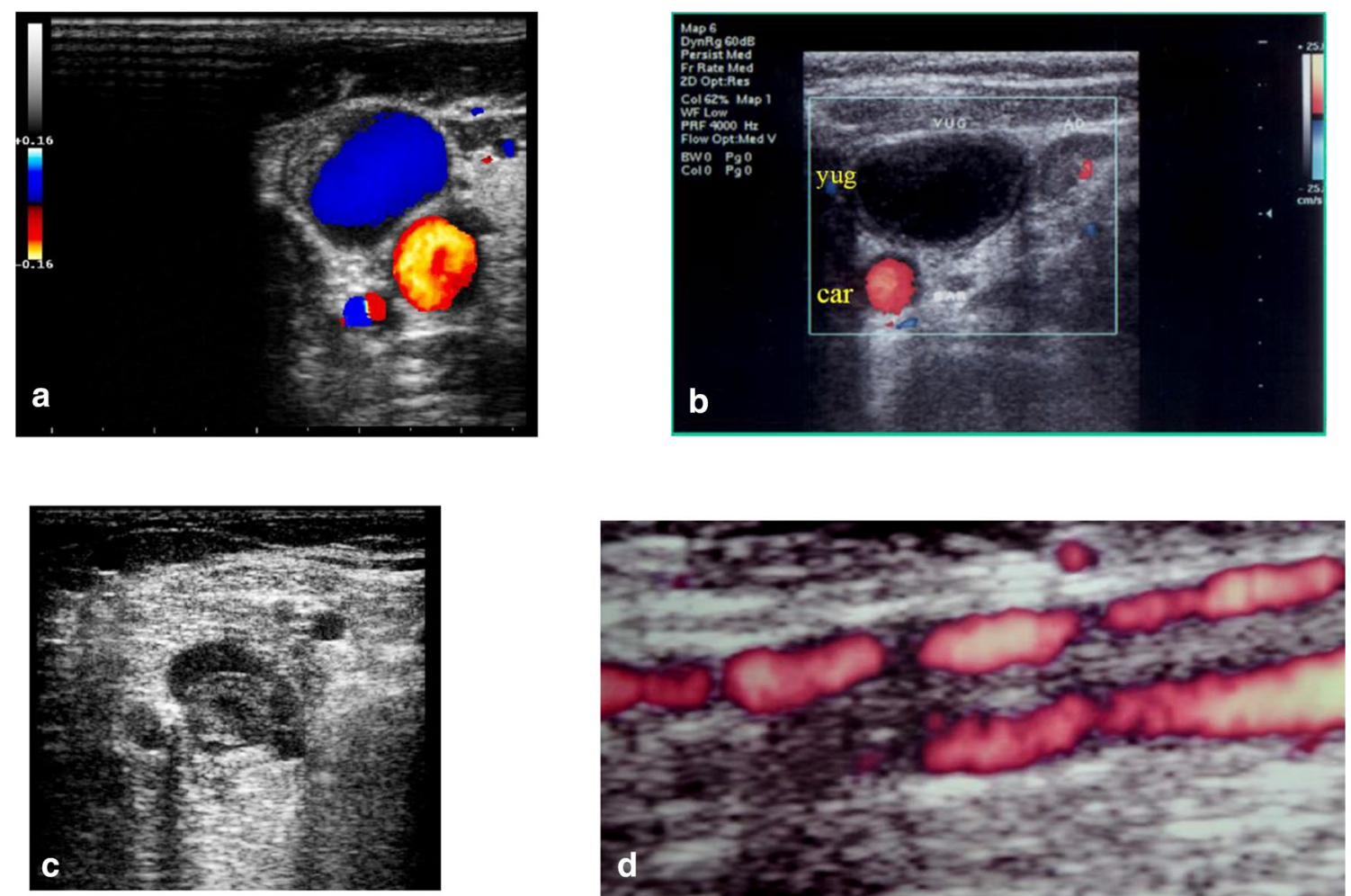

Fig. 7 Venous thrombosis. a Partial thrombosis of right yugular vein: color Doppler (jugular vein in blue, carotid artery in red). b Complete acute hypoechoic thrombosis of left jugular vein (yug): transverse view. Carotid artery is seen in red (car). c Post trauma partial venous thrombosis. $\mathbf{d}$ Chronic thrombosis: partial recanalization: multiple color tunnels are seen inside the thrombus 

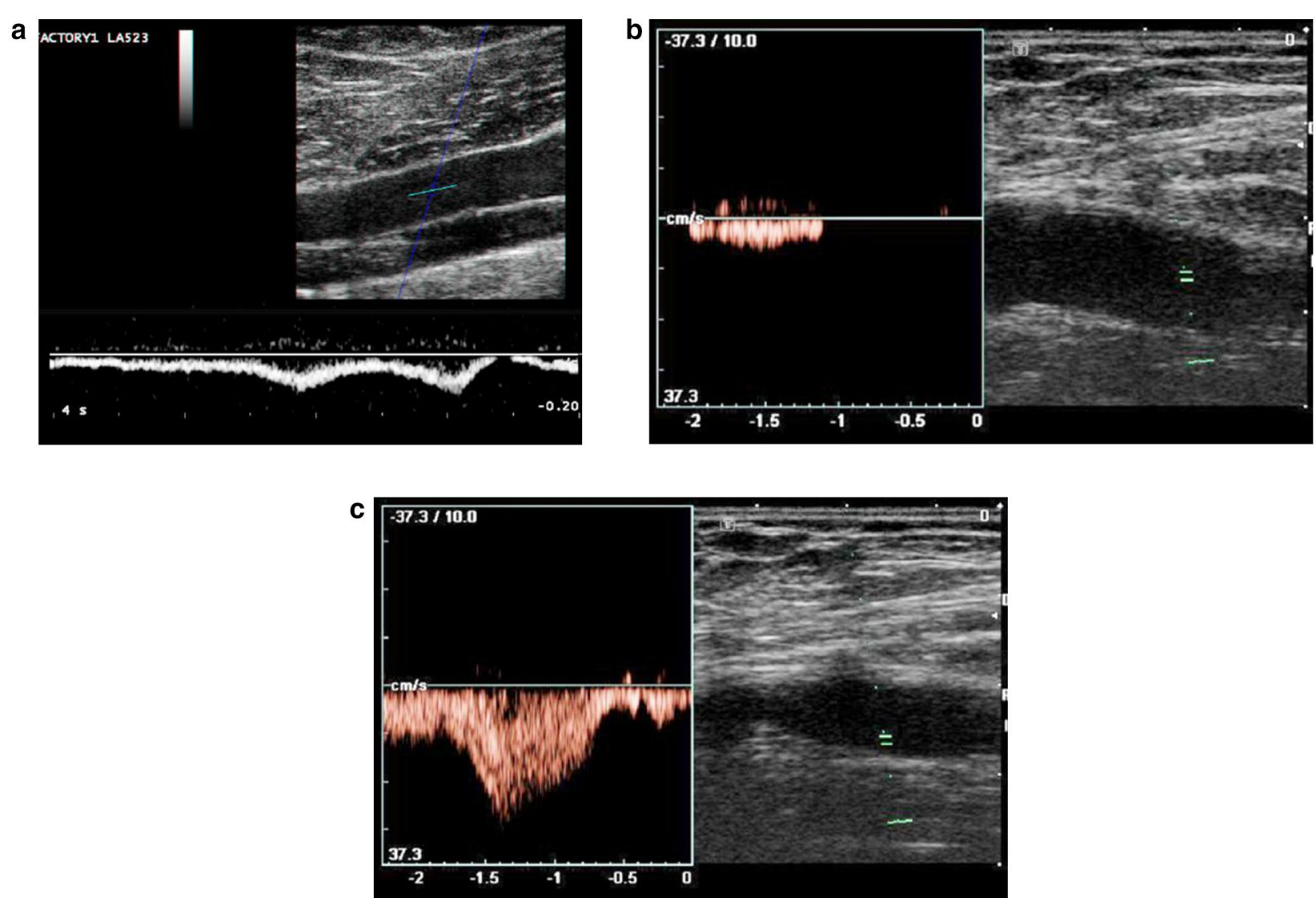

Fig. 8 Normal spectral Doppler venous flow. a respiratory variability, $\mathbf{b}$ a proximal compression or a Valsalva maneuver cause stop of the flow, $\mathbf{c}$ the distal compression of the vein cause an increase of the velocity of the flow (augmentation)

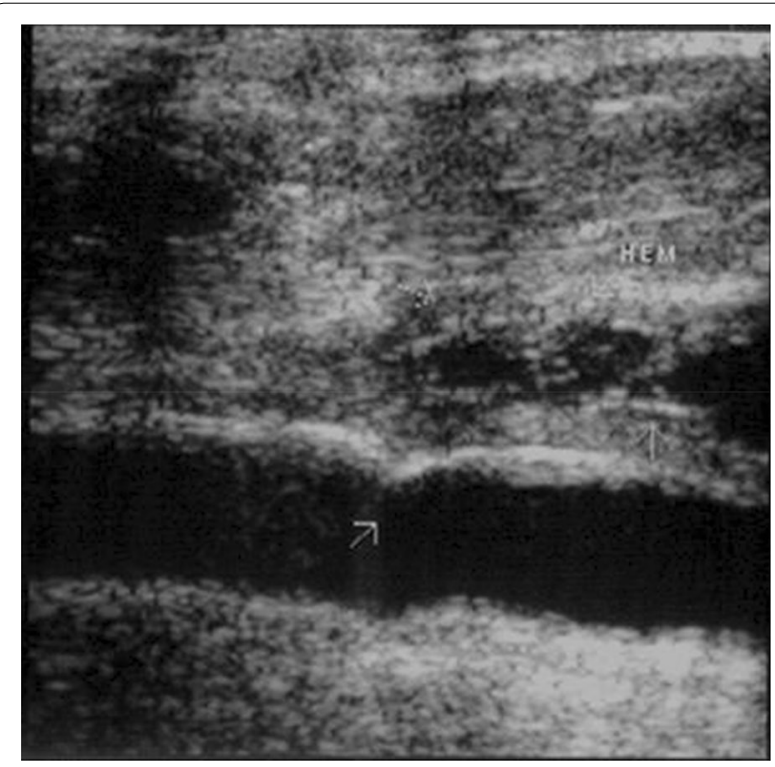

Fig. 9 B mode of carotid artery after a penetrating wound caused by a knife: soft tissues edema and irregularity of the anterior wall of the carotid artery is clearly observed

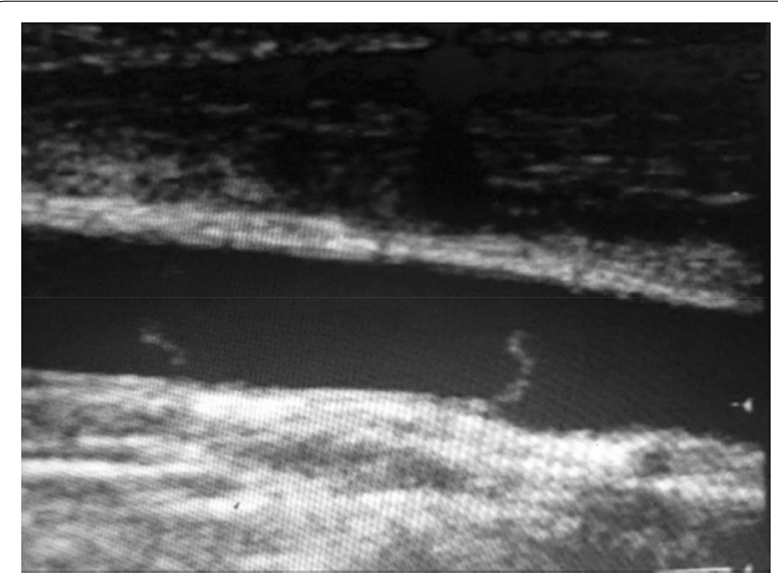

Fig. 10 Post traumatic carotid artery intimal flap. B mode. Echogenic flap into the lumen 

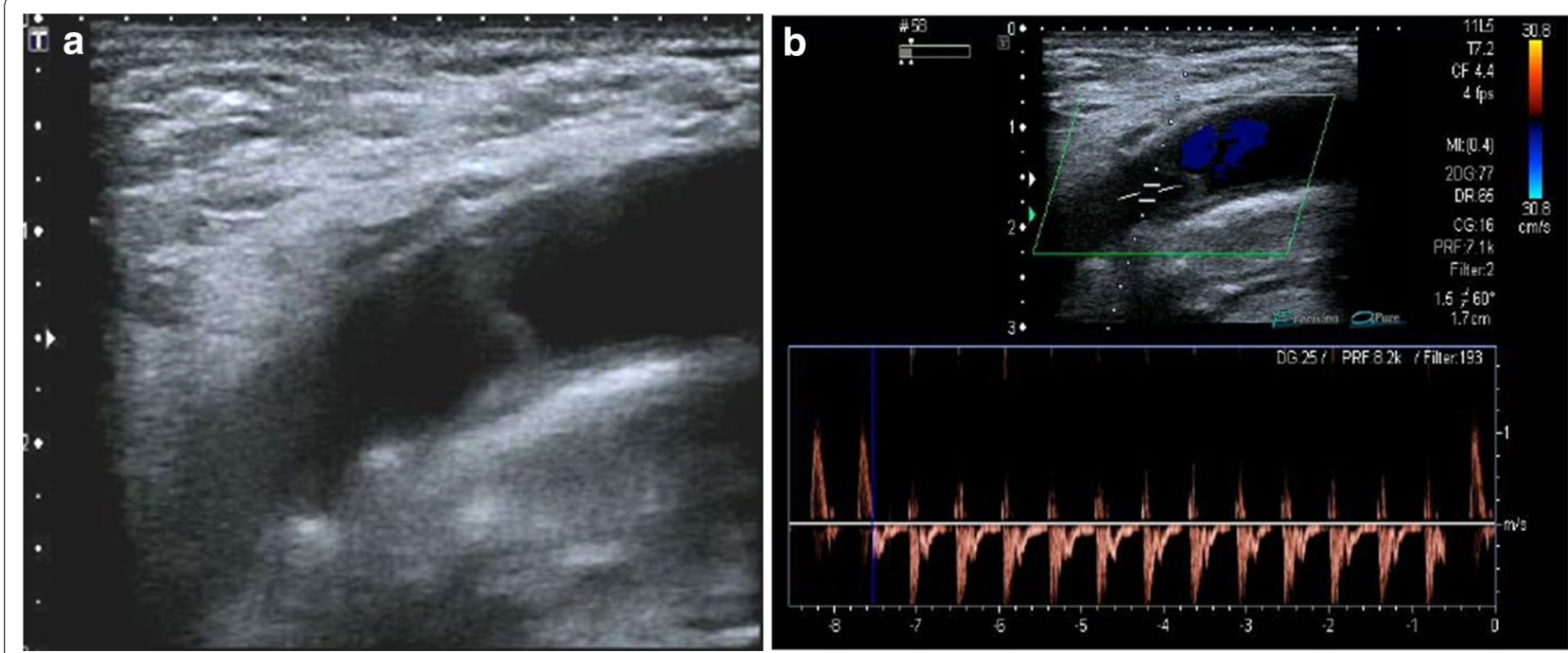

Fig. 11 Post traumatic femoral artery intimal flap. a B mode. Small echogenic flap into the lumen. b Turbulent flow with change of direction of the flow was seen moving the sample volume near the moving flap

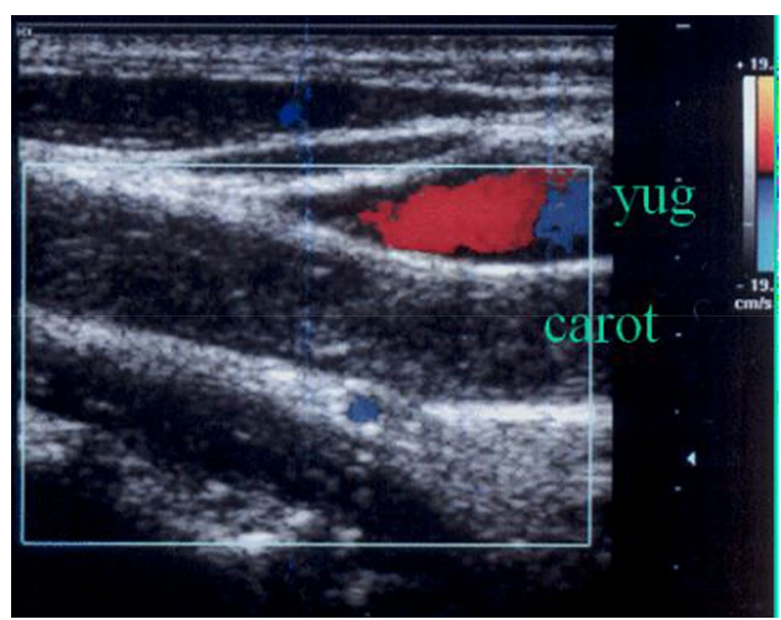

Fig. 12 Complete post traumatic carotid artery thrombosis. Longitudinal view of the neck shows abscence of flow in the carotid artery (carot). The jugular vein is partially visualized (in red and blue) an anechoic or hypoechoic image, similar to a hematoma, but containing moving echoes (pulsatile hematoma), may be observed. Occasionally, it can swell during systole. The lumen can be partially filled by echogenic structures due to the presence of thrombus. When using CFD evaluation, the diagnosis is made by showing the typical swirling motion that causes a colorized yin-yang sign (Fig. 13). This sign is cause by the circular motion of the blood inside the pseudoaneurysm cavity. During systole, the flow goes towards the pseudoaneurysm cavity (red) and during diastole the blood moves back to the arterial lumen (blue) [33, 35]. Inside the pseudoaneurysm, turbulent flow is recorded with the spectral analysis. If we place the sample volume on the neck of the pseudoaneurysm, we might be able to see a characteristic flow pattern known as "to-and-fro." This is a bidirectional flow caused by the continuous entry and exit of blood from the artery
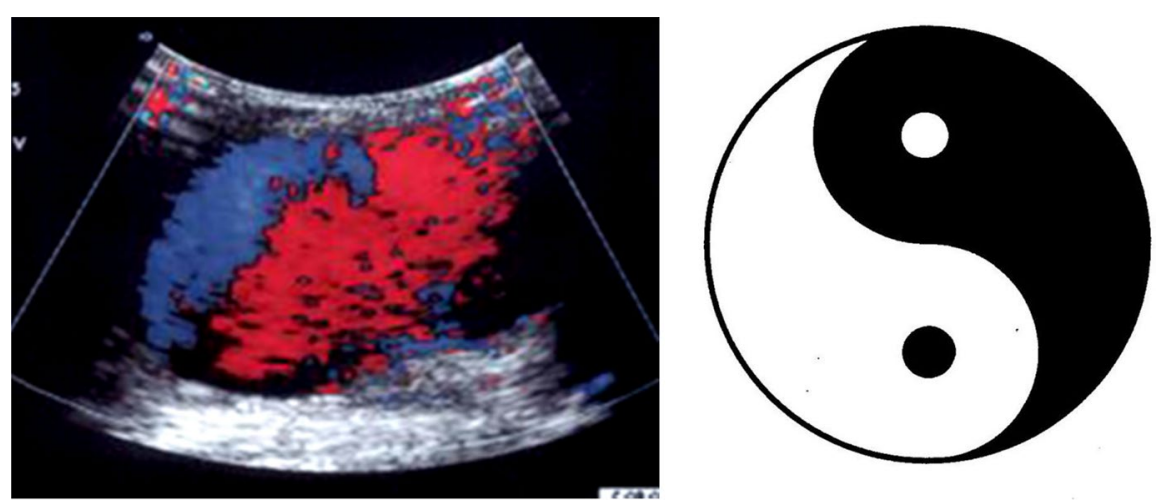

Fig. 13 Pseudoaneurism: color Doppler aspect: colorized yin yang sign 
to the pseudoaneurysm (Figs. 14, 15, 16). Ultrasound is also used to treat of iatrogenic femoral pseudoaneurysm. Ultrasound-assisted arterial compression, thrombin

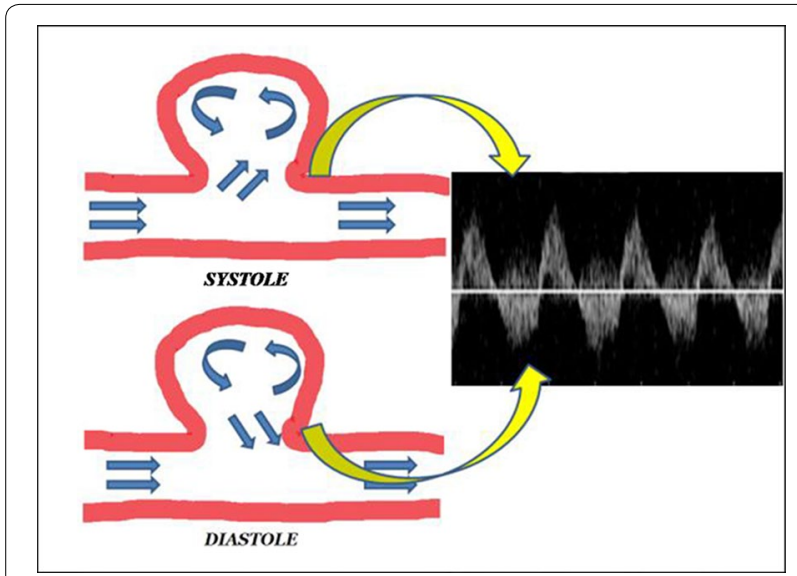

Fig. 14 Schematic representation of the movement of the flow into a pseudoaneurism causing a characteristic biphasic flow in the neck of the PA injection, and further monitoring have demonstrated to have high efficacy and low complications rates [36, 37].

\section{Mixed arterial and venous injuries}

An Arteriovenous fistula (AVF) is a permanent communication between an artery and a vein. Depending of the size, it may cause hemodynamic alterations with cardiac effects [38, 39]. It can be congenital or acquired (i.e., traumatic, iatrogenic) [40, 41]. The vein caliber and local venous pressure usually increases due to different pressure between arteries and the veins. These modifications are followed by a phenomenon called arterialization of the flow and the vessel. It is unusual to diagnose AVF soon after trauma. A murmur and thrill on the site of the fistula may be present. With B-mode, the presence of an anechoic, anfractuous structure communicating the vein and artery may be seen. CFD examination may reveal the presence of a color mosaic (aliasing), due to the presence of multiple velocities inside the fistula, causing high flow turbulence. The pulsed Doppler spectral analysis may show high systolic and diastolic velocities with
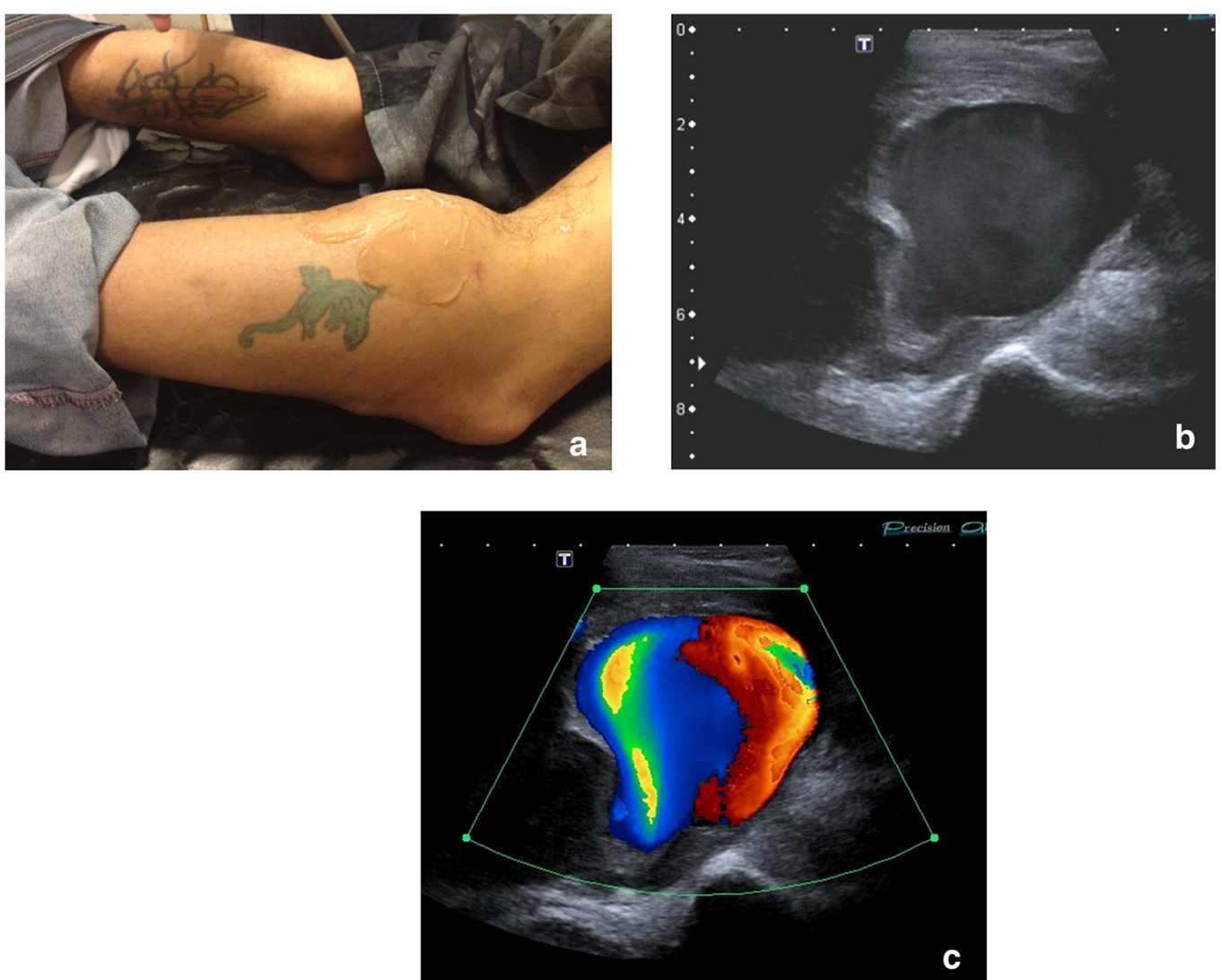

Fig. 15 Popliteal pseudoaneurism (gun shot wound one week before). a Left popliteal mass. b B mode: hipoechoic liquid image with swirling movements in real time. c Color Doppler: Yin Yang colorized sign 


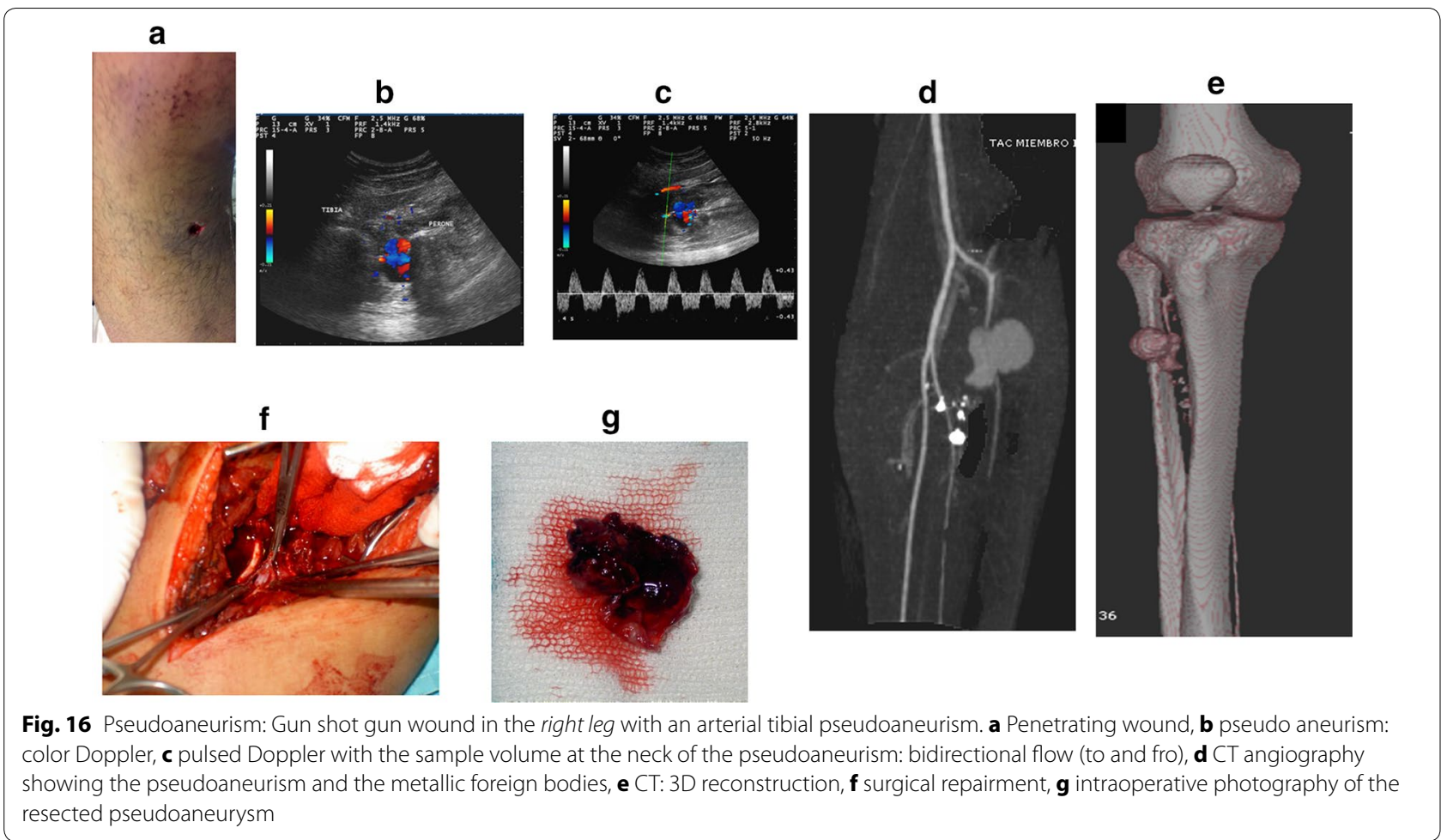

loss of systolic windows due to the wide velocity range (Figs. 17, 18).

\section{Distal flow analysis}

The presence of triphasic flow in the distal arteries of the lower extremities may be interpreted as an indication of absence of lesion in the proximal arteries [21] (Fig. 19). Arterial injuries of the lower limbs, (being acute or chronic) can cause distal alteration of the flow (Fig. 20). The absence of flow or the presence of a biphasic or monophasic flow may be considered pathologic and further investigation may be necessary [42]. If an arterial injury is suspected, the detection of triphasic flow in distal arteries of the lower limbs may help to rapidly rule out a significant vascular injury with $100 \%$ sensitivity (Montórfano et al. The FAST D protocol: A

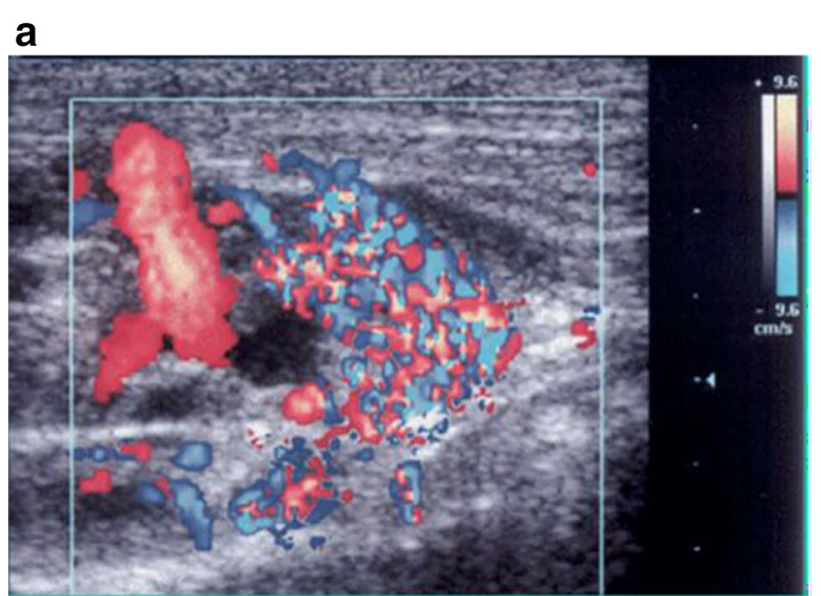

b

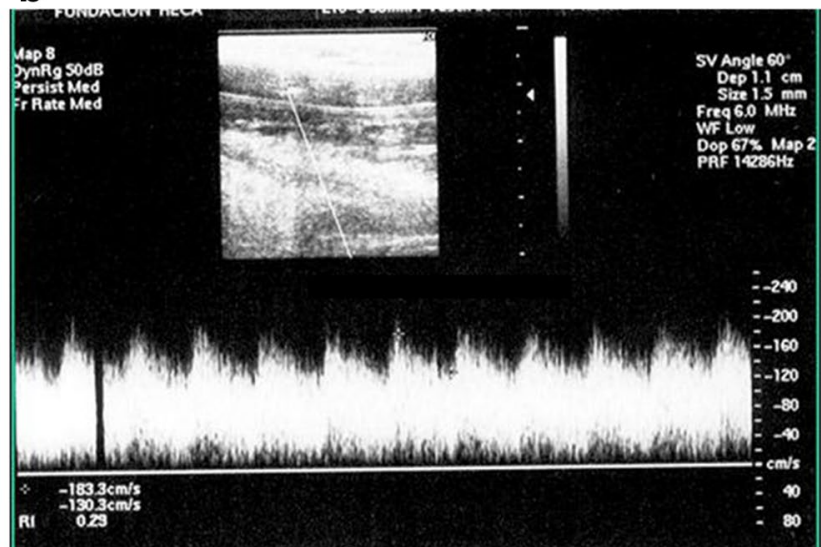

Fig. 17 Arterio venous fistula. a Color Doppler aspect: mosaic of colours representing multiple different velocities. b Spectral analysis: high systolic and diastolic velocities 

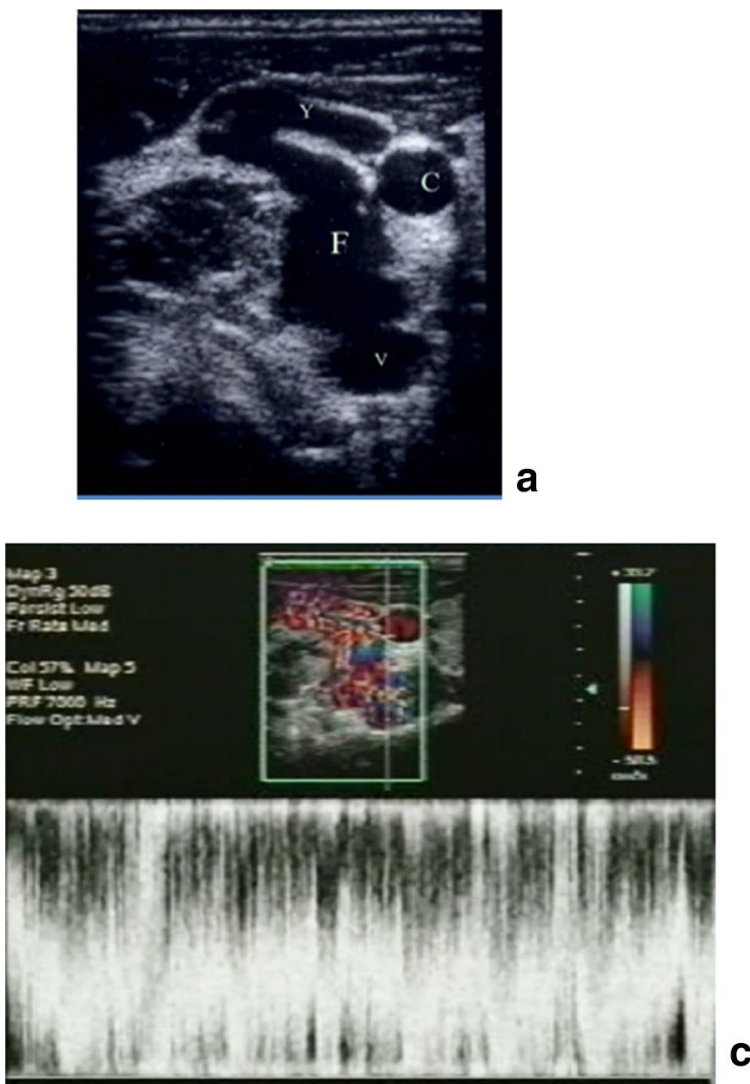
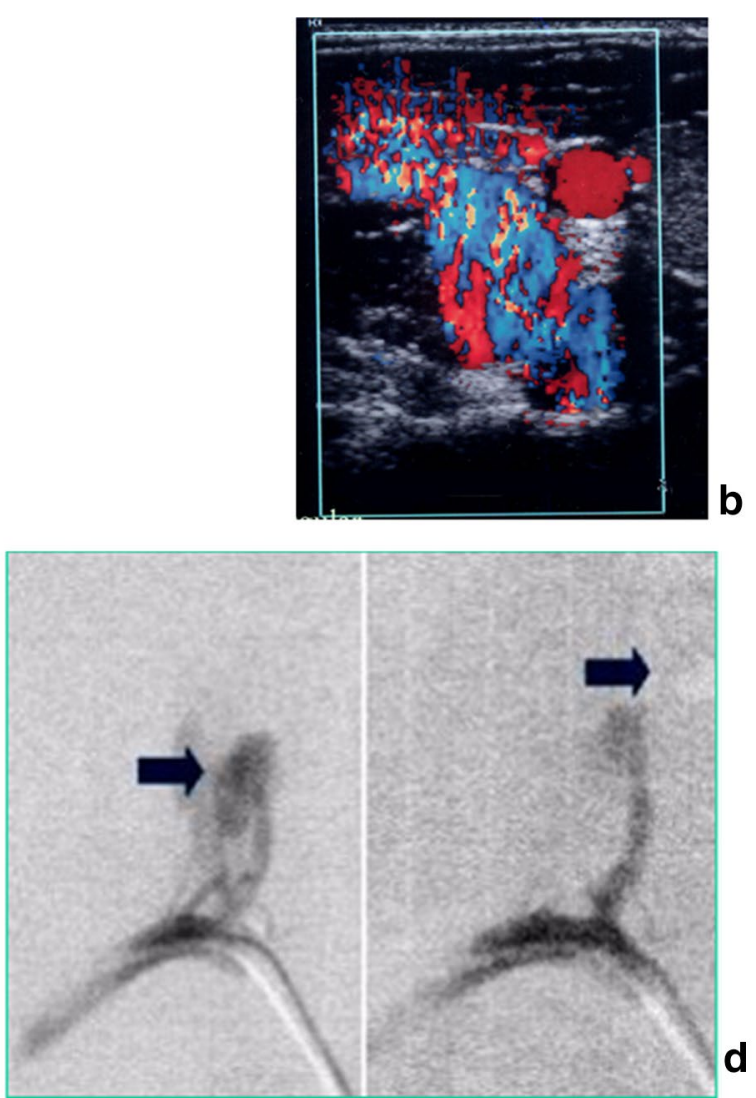

d

Fig. 18 Arterio venous fistula: gun shot wound in the right side of the neck. Arteriovenous traumatic fistula between right yugular vein and right vertebral artery. a B mode: anechoic image connecting right yugular vein with the right vertebral artery. C carotid artery, $V$ vertebral artery, $Y$ yugular vein, $F$ fistula. $\mathbf{b}$ Color Doppler: mosaic of colours representing different velocities. Color in soft tissues surrounding the FAV representing the thrill. c Pulse Doppler: spectral analysis with hight velocities spectrum and turbulent flow. d Angiographic findings
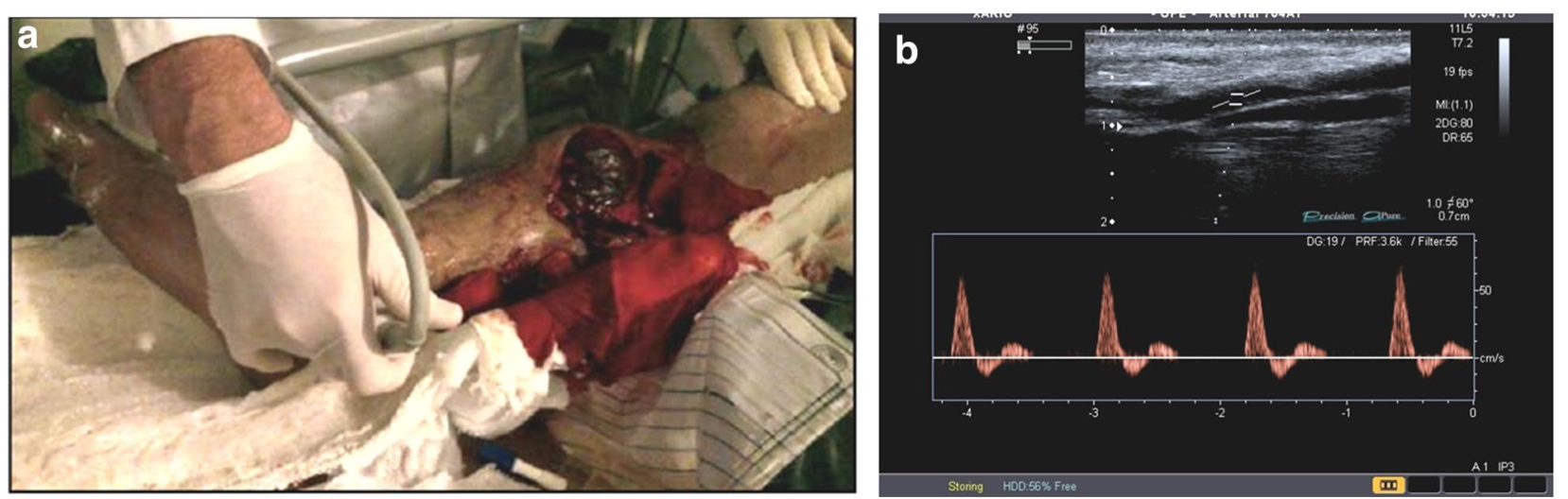

Fig. 19 Open fracture of the tibia. a Displaced long bone fracture with segment exposure. Exploration of distal pulses. b Normal triphasic flow 

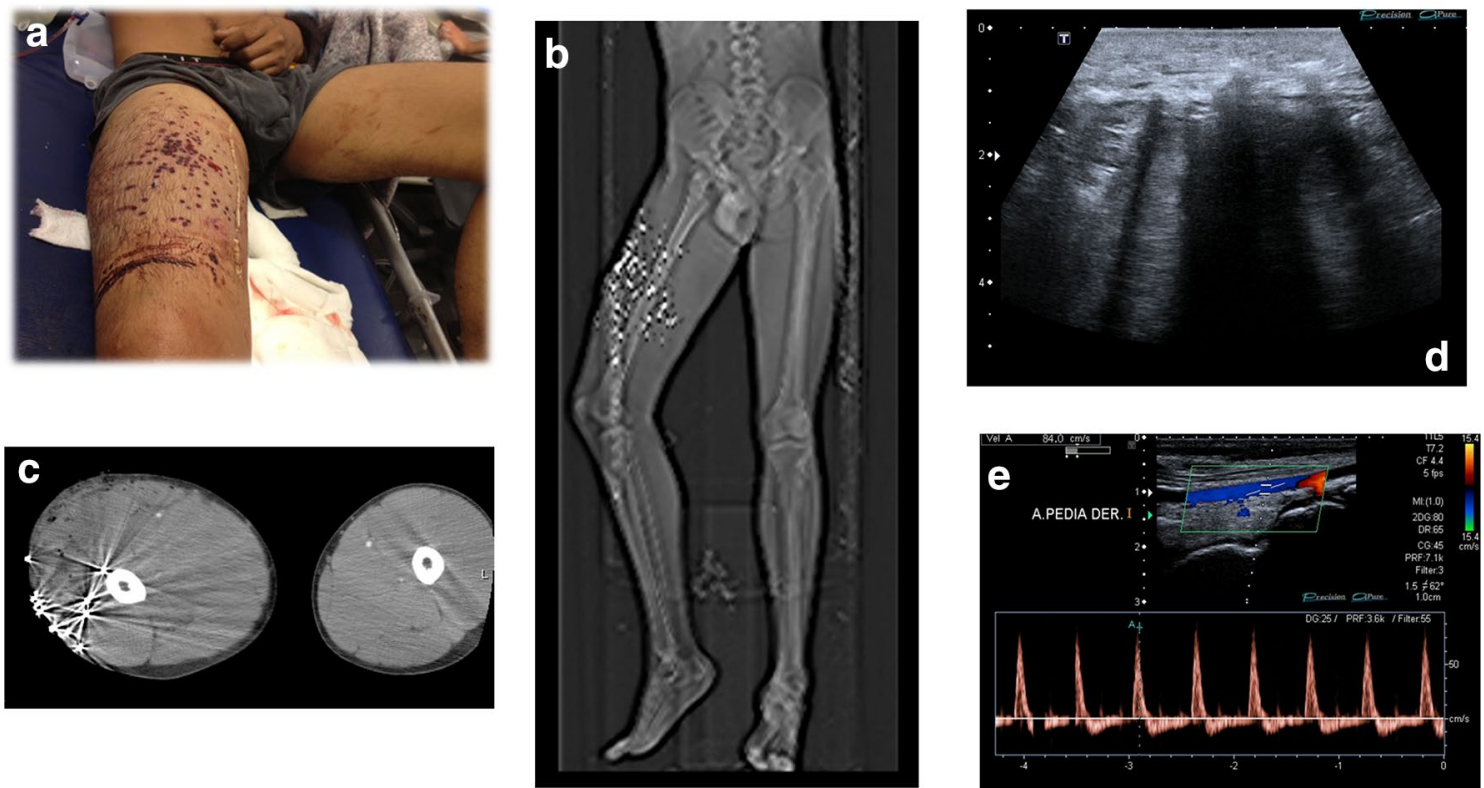

Fig. 20 External compression. a Multiple penetrating gun shot wounds in the right tight. b CT scan. c CT multiple bullets. Increase diameter of the right tight. $\mathbf{d}$ Ultrasound showed the metallic foreign bodies with acoustic shadow and edema of the soft tissues. e Color Doppler showed no vascular lesion in the right tight Pulse wave Doppler showed lost of the triphasic normal flow in distal arteries caused by external compression of the arteries cause by edema and tumefaction

simple method to rule out traumatic vascular injuries of the lower extremities. Submitted to Critical Ultrasound Journal).

\section{Eco Doppler ultrasound monitoring}

B-mode ultrasound and Color flow Duplex Doppler ultrasound can also be used for monitoring and followup after endovascular or surgical treatment of vascular injuries [41, 43-46]. B-mode evaluation is useful for monitoring the soft tissue surrounding the lesion, and for ruling in and ruling out hematomas and fluid collections. The Color flow Duplex Doppler technique is used for the evaluation of blood flow patterns in the anastomotic area, proximal and distal flow characteristics, the presence of pathological flow variation, and eventual occlusions [21] (Fig. 21).

\section{Conclusions}

When there are no hard signs of vascular injury and the patient is stable, imaging methods can aid in the localization and diagnosis of trauma-related vascular lesions. While angiography still remains the gold standard for the assessment of traumatic vascular injuries of the limbs and neck, other less invasive imaging modalities have gained popularity in the recent years and are routinely used. Point-of-care ultrasound and Color flow duplex Doppler ultrasound are widely available, noninvasive, sensible and specific techniques that can be used bedside, 

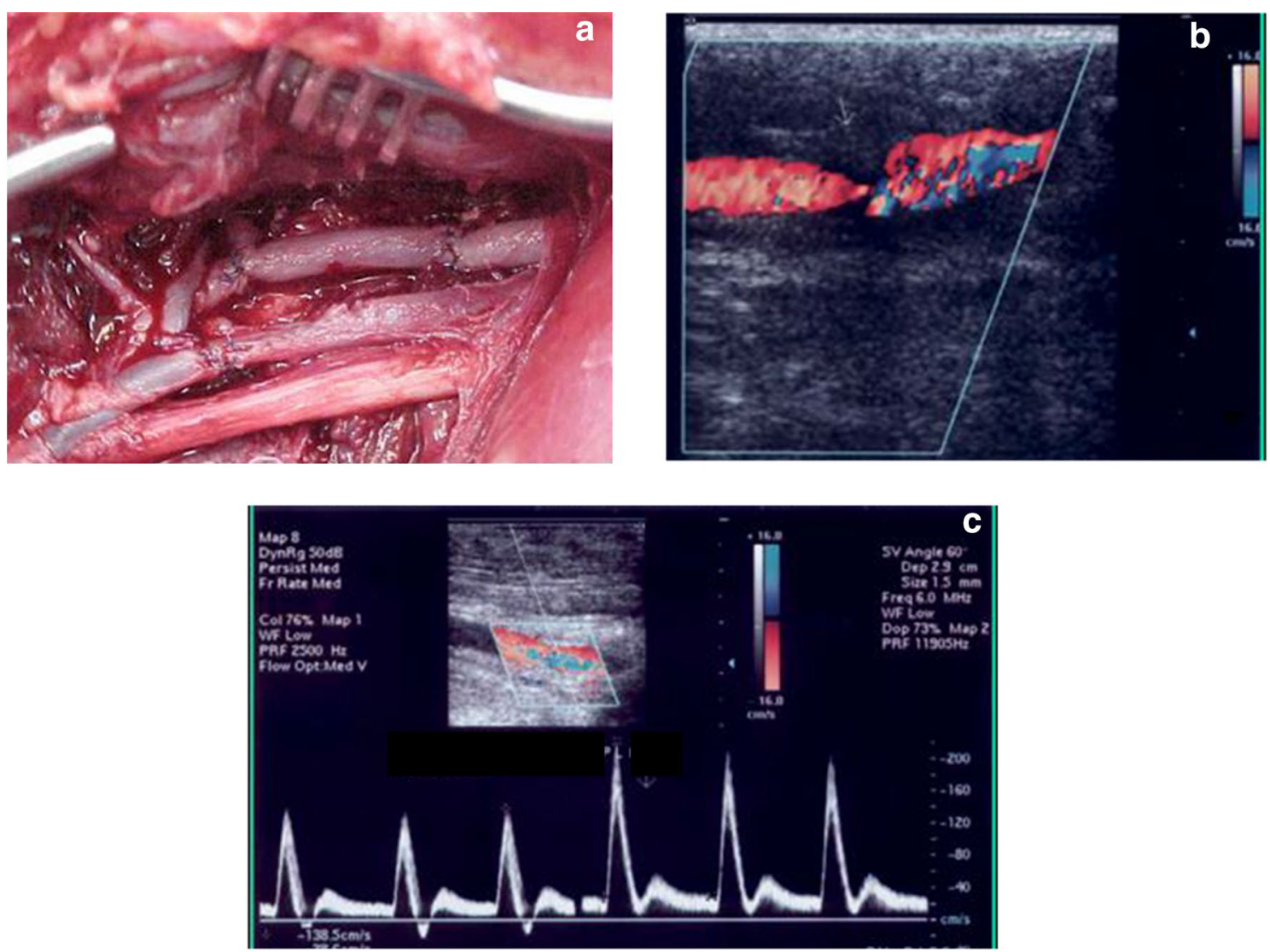

Fig. 21 Gun shot femoral artery injury. Post operative follow up. a Surgical repairment with vein interposition. b Color flow: stenosis with turbulent flow in the anastomosis. $\mathbf{c}$ Increase of the velocity at the level of the stenosis in the pulsed Doppler spectrum

as a first approach for a prompt diagnosis and follow-up of trauma-related vascular injuries, and for an integrated management of trauma patients.

\section{Authors' contributions}

MAM: Manuscript writing and final review, provided figures. FP: Manuscript writing. LV: Manuscript writing. OC: Manuscript writing. SGN: Manuscript writing and edition. LMM: Manuscript writing and edition. All authors read and approved the final manuscript.

\section{Author details}

1 Present Address: Department of Ultrasound, Clemente Álvarez Emergency Hospital, Av. Pellegrini 3205, 2000 Rosario, Santa Fe, Argentina. ${ }^{2}$ Emergency Medicine Residency, University of Pavia, Strada Nuova 65, 27100 Pavia, Italy.

\section{Acknowledgements}

Not applicable.

\section{Competing interests}

The authors declare that they have no competing interests.

\section{Availability of data and materials}

Yes.

\section{Ethics approval and consent to participate}

The internal review board of the hospital approved this study and waived the requirement for informed consent.
Received: 12 December 2016 Accepted: 10 February 2017 Published online: 16 February 2017

\section{References}

1. WHO-World Health Organization (2014) Injuries and violence, the facts

2. Skarpedas S et al (2009). The costs of violence. Social Development Department. The World Bank

3. Chelala C (1997) Violence in the Americas: The Social Pandemic of the 20th Century. Pan American Health Organization, Washington, DC

4. Rozycki GS et al (2003) Blunt vascular trauma in extremities: diagnosis, management and outcome. J Trauma 55:814-824

5. Soto GS et al (2004) Trauma vascular periférico. Cuad Cir 18:91-97

6. Martín Trenor A (2005) Traumatismos vasculares periféricos. Rev Med Univ Navarra 49(2):24-31

7. Torres Carranza SA (2006) Trauma vascular de las extremidades y un poco de su historia. Trauma 9(3):83-86

8. Suárez CA et al (2007) Heridas por armas de fuego y traumas vasculares: una ventana a la violencia civil en Caracas. Gac Méd Caracas 115(4):304-312

9. Sonneborn $\mathrm{R}$ et al (2002) Vascular trauma in Latin America. A regional survey. Surg Clin North Am 82:189-194

10. Fogelman MJ, Stewart RD (1956) Penetrating wounds of the neck. Am J Surg 91:581-593

11. Campbell FC, Robbs JV (1980) Penetrating injuries of the neck: a prospective study of 108 patients. Br J Surg 67:582-586 
12. Willis BK et al (1994) The incidence of vertebral artery injury after midcervical spine fracture or subluxation. Neurosurgery 34:435-442

13. Hoff SJ et al (1994) Analysis of blunt and penetrating injury of the innominate and subclavian arteries. Am Surg 60:151-154

14. Frykberg ER (1995) Advances in the diagnosis and treatment of extremity vascular trauma. Surg Clin North Am 75:207-223

15. Gaitini D et al (2008) Sonographic evaluation of vascular injuries. J Ultrasound Med 27:95-107

16. Bergstein JM, Blair JF, Edwards J et al (1992) Pitfalls in the use of color-flow duplex ultrasound for screening of suspected arterial injuries in penetrated extremities. J Trauma 33:395-402

17. Fry WR, Smith RS, Sayers DV, Henderson VJ, Morabito DJ, Tsoi EK et al (1993) The success of duplex ultrasonographic scanning in diagnosis of extremity vascular proximity trauma. Arch Surg 128(12):1368-1372

18. Wani ML, Sheikh MT, Nayeem-ul-Hassan A, Irshad I, Ahangar AG, Ganie FM, Sheikh MT, Wani SN (2014) Int Cardiovasc Res I 8 (1)

19. Neri L, Storti E, Lichtenstein D (2007) Towards an ultrasound curriculum. Crit Care Med 35(5):S290-S304

20. Lyon M, Blaivas M (2003) Evaluation of extremity trauma with sonography. J Ultrasound Med 22:625-630

21. Polak J (1992) Peripheral vascular sonography. A practical guide. Williams \&Wilkins, Philadelphia

22. Noble VE et al (2007) Manual of emergency and critical care ultrasound. Cambridge University Press, Cambridge

23. Schwartz M, Weaver F, Yellin A, Ralls P (1993) The utility of Color flow Doppler examination in penetrating extremity arterial trauma. Am Surg 59:375-378

24. Schoder M, Prokof M, Lammer J (2002) Traumatic injuries: imaging and intervention of large arterial trauma. Eur Radiol 12:1617-1631

25. Lensing et al (1997) A comparison of compression ultrasound with Color Doppler ultrasound for the diagnosis of symptomless postoperative deep vein thrombosis. Arch Int Med 157:765-768

26. Birdwell et al (1998) The clinical validity of normal compression ultrasonography in outpatients suspected of having deep venous thrombosis. Ann Intern Med 128:1-7

27. Burnside PR et al (2008) Systematic review of emergency physician-performed ultrasonography for lower-extremity deep vein thrombosis. Acad Emerg Med 15:493-498

28. Blaivas M, Lambert MJ, Harwood RA et al (2000) Lower-extremity Doppler for deep venous thrombosis - can emergency physicians be accurate and fast? Acad Emerg Med 7:120-126

29. Theodoro DL, Blaivas M, Duggal D et al (2002) Emergency physician-performed lower extremity doppler results in significant time savings. Acad Emerg Med 9:541

30. Bernardi E et al (2008) Serial 2-point ultrasonography plus D-dimer vs whole-leg color-coded Doppler ultrasonography for diagnosing suspected symptomatic deep vein thrombosis: a randomized controlled trial. JAMA 300(14):1653-1659
31. Hernández-Maldonado JJ, Padberg FT Jr, Teehan E, Neville R, DeFouw D, Durán WN, Hobson RW (1993) Arterial intimal flaps: a comparison of primary repair, aspirin, and endovascular excision in an experimental model. J Trauma 34(4):565-569; (discussion 569-70).

32. Jr Neville RF, Yasuhara H, Watanabe BI, Canady J, Durán W, Hobson RW (1991) Endovascular management of arterial intimal defects: an experimental comparison by arteriography, angioscopy, and intravascular ultrasonography. J Vasc Surg 13(4):496-502

33. Mitchell DG, Needleman L, Bezzi M, Goldberg BB et al (1987) Femoral artery pseudoaneurysm: diagnosis with conventional duplex and Color Doppler US. Radiology 165:687-690

34. Olinde AJ (1989) Traumatic subclavian axillary artery aneurysm. J Vasc Surg 11:848-849

35. Yetkin U, Gurbuz A (2003) Post-traumatic pseudoaneurysm of the brachial artery and its surgical treatment. Tex Heart Inst J 30:293-297

36. Vázquez V et al (2003) Utilidad de la inyección de trombina dirigida por ecografía en los seudoaneurismas femorales iatrogénicos después del fracaso de la compresión. Med Clin (Barc) 121(2):53-57

37. Eisenberg L et al (1999) Sonographically guided compression repair of pseudoaneurysms: further experience from a single institution. AJR Am J Roentgenol 173:1567-1573

38. Li JC et al (2002) Diagnostic criteria for locating acquired arteriovenous fistulas with color Doppler sonography. J Clin Ultrasound 30(6):336-342

39. Bowers AL et al (2008) Traumatic lower extremity arteriovenous fistulae in children. Orthopedics 31:6

40. Turnipseed WD, Hurschler C, Vanderby R Jr (1995) The effects of elevated compartment pressure on tibial arteriovenous flow and relationship of mechanical and biochemical characteristics of fascia to genesis of chronic anterior compartment syndrome. J Vasc Surg 21:810-816

41. Scalea TM, Sclafani SJ (1991) Angiographically placed balloons for arterial control. A description of a technique. J Trauma 31:1671-1677

42. Robbs JV, Carrim AA, Kadwa AM, Mars M (1994) Traumatic arterio-venous fistula: experience with 202 patients. Br J Surg 81:1296-1299

43. Kang SS et al (2000) Expanded indications for ultrasound-guided thrombin injection of pseudoaneurysms. J Vasc Surg 31:289-298

44. Magge D, Farber A, Vladimir F, Woodson J, Collins K, Shaw P, Gibbons $G$ (2008) Diagnosis and management of traumatic pseudoaneurysm of the carotid artery: case report and review of the literature. Vascular 16(6):350-355

45. Hanson JM, Atri M, Power N (2008) Ultrasound-guided thrombin injection of iatrogenic groin pseudoaneurysm: Doppler features and technical tips. Br J Radiol 81:154-163

46. Fusonie GE, Edwards JD, Reed AB (2004) Covered stent exclusion of blunt traumatic carotid artery pseudoaneurysm: case report and review of the literature. Ann Vasc Surg 18(3):376-379

\section{Submit your manuscript to a SpringerOpen ${ }^{\circ}$ journal and benefit from:}

- Convenient online submission

- Rigorous peer review

- Immediate publication on acceptance

- Open access: articles freely available online

- High visibility within the field

- Retaining the copyright to your article

Submit your next manuscript at $\boldsymbol{\nabla}$ springeropen.com 